\title{
Relationship Between Hispanic Nativity, Residential Environment, and Productive Activity Among Individuals with Traumatic Brain Injury: A TBI Model Systems Study
}

Anthony H. Lequerica, PhD Amanda Botticello, PhD, John O'Neill, PhD,
Jean Lengenfelder, PhD, Denise Krch, PhD, \& Nancy D. Chiaravalloti, PhD

Kessler Foundation, East Hanover, NJ

Rutgers, New Jersey Medical School, Newark, NJ

Angelle M. Sander, $\mathrm{PhD}$

Department of Physical Medicine \& Rehabilitation, Baylor College of Medicine and Harris Health System, and Brain Injury Research Center, TIRR Memorial Hermann, Houston, TX

Tamara Bushnik, $\mathrm{PhD}$

Rusk Rehabilitation, NYU Langone Health, New York, NY

Jessica M. Ketchum, PhD

Craig Hospital Research Department, Englewood, CO

Traumatic Brain Injury Model Systems National Data and Statistical Center, Englewood

Flora M. Hammond, MD

Department of Physical Medicine \& Rehabilitation, Indiana University School of Medicine, Rehabilitation Hospital of Indiana, Indianapolis, IN

Kristen Dams-O'Connor PhD

Department of Rehabilitation Medicine, Department of Neurology

Icahn School of Medicine at Mount Sinai, New York, NY

Elizabeth Felix, $\mathrm{PhD} \&$ Doug Johnson-Greene, $\mathrm{PhD}$

Department of Physical Medicine \& Rehabilitation, University of Miami Miller School of Medicine, Miami, FL

\section{Conflicts of Interest and Sources of Funding}

This work was funded by grants from the National Institute on Disability, Independent Living, and Rehabilitation Research (NIDILRR) to the following:

Northern New Jersey Traumatic Brain Injury System (Grant Number 90DP0032)

Rusk Rehabilitation Traumatic Brain Injury Model System (Grant Number 90DP0047)

Texas Traumatic Brain Injury Model System of TIRR (Grant Numbers 90DP0028 \& 90DPTB001601), New York Traumatic Brain Injury Model System at Mount Sinai (Grant Number 90DP0038), Indiana Traumatic Brain Injury Model System (Grant number 90DP0036), South Florida Traumatic Brain Injury Model System (Grant Number 90DP0046), Rocky Mountain Regional Brain Injury System (Grant \#90DP0034-01-00), Traumatic Brain Injury Model Systems National Data and Statistical Center (Grant \# 90DP0084-01-00)

Authors have no conflicts of interest to disclose. The research was conducted consistent with ethical guidelines for the conduct of research.

This is the author's manuscript of the article published in final edited form as:

Lequerica, A., Botticello, A., O’Neill, J., Lengenfelder, J., Krch, D., Chiaravalloti, N., ... Johnson-Greene, D. (2019). Relationship Between Hispanic Nativity, Residential Environment, and Productive Activity Among Individuals With Traumatic Brain Injury: A TBI Model Systems Study. Journal of Head Trauma Rehabilitation, 34(1). https://doi.org/10.1097/HTR.0000000000000398 


\begin{abstract}
Objective: To examine the influence of nativity and residential characteristics on productive activity among Hispanics at 1 year after traumatic brain injury (TBI).

Setting: Acute rehabilitation facilities and community follow-up.

Participants: 706 Hispanic individuals in the TBI Model Systems National Database.

Design: Secondary data analysis from a multicenter longitudinal cohort study.

Main Measures: Nativity (foreign-born or US native), productive activity derived from interview questions regarding employment status, and other demographic information. Census data was extracted by zip code to represent residential characteristics of aggregate household income and proportion of foreign language speakers (FLS).
\end{abstract}

Results: Among foreign-born individuals with TBI, those living in an area with a higher proportion of FLS were 2.8 times more likely to be productive than those living in areas with a lower proportion of FLS. Among individuals living in an area with a lower proportion of FLS, US-born Hispanics were 2.7 times more likely to be productive compared with Hispanic immigrants.

Conclusion: The relationship between nativity and productive activity at 1 year post-TBI was moderated by the residential proportion of FLS. Findings underscore the importance of considering environmental factors when designing vocational rehabilitation interventions for Hispanics after TBI.

Key Words: Traumatic Brain Injury, Ethnicity, Social Environment, Productivity 


\section{INTRODUCTION}

Traumatic Brain Injury (TBI) is a major contributor to mortality, morbidity, and disability in the United States (US), where at least 5.3 million are living with a TBI-related disability ${ }^{1-3}$. The costs associated with TBI are staggering; direct medical costs combined with indirect costs, such as lost productivity total an estimated $\$ 60$ billion in the United States in a single year ${ }^{4}$. Individuals who sustain moderate or severe injuries often face longstanding cognitive, physical, emotional, behavioral, and functional problems that can negatively impact educational and occupational achievement ${ }^{5}$. Involvement in productive activities such as school and work are central to a person's identity and sense of engagement in a community. Previous research has demonstrated that those who are able to work or attend school have higher life satisfaction after the $\mathrm{TBI}^{6}$. Unfortunately, a large proportion (over $60 \%$ ) of individuals of working age are unable to return to work within two years after discharge from inpatient rehabilitation ${ }^{5}$. A variety of factors have been found to be associated with unemployment outcomes after TBI; these include older age, injury severity, alcohol use, less than high school education, under-employment or unemployment at the time of injury, and race/ethnicity ${ }^{7-13}$

With the US population becoming increasingly diverse, it is important to understand how issues of race/ethnicity impact outcomes after TBI. Hispanics are the second-largest racial/ethnic group after Whites. In 2016, the Hispanic population in the US reached almost 58 million (18\% of the nation's population), and is projected to grow to 107 million (24\% of the population) by 2065 14,15. The US Hispanic population is comprised of individuals with ancestry from various countries, with those of Mexican and Puerto Rican descent accounting for greater than two thirds of all US Hispanics. Five other Hispanic origin groups have populations of greater than 1 million - Salvadorans, Cubans, Dominicans, Guatemalans and Colombians ${ }^{16}$. With respect to 
employment, the US Census reports that $62.4 \%$ of Hispanics 16 and older were employed in $2016^{17}$. Sevak and colleagues analyzed disability employment data from the 2009-2011 American Community Survey (ACS) data, and found that $36.6 \%$ of Hispanics aged 25 to 64 with disabilities were employed, whereas $73.8 \%$ of those without disabilities were employed ${ }^{18}$. Productive Activity among Hispanics after TBI

Research has indicated that employment rates are lower ${ }^{19}$ and less stable over time ${ }^{20,21}$ for minorities compared to Whites. Unfortunately, earlier studies aggregated Hispanics and Blacks into a single category for analysis, so the specific employment trends for Hispanics after TBI was not consistently reported across studies. In a sample of 3,940 persons with moderate-severe TBI enrolled in the TBI Model Systems database and followed at 1, 2, or 5 years post-injury, ArangoLasprilla and colleagues (2011) specifically demonstrated that Hispanics have lower odds of being employed compared to Whites at 1 and 2 years post-injury, even after adjusting for demographic and injury characteristics ${ }^{22}$. Conclusions of this study were limited by the lack of inclusion of a measure of socioeconomic status in the database at that time.

Sander et al. (2009) controlled for household income when studying the relationship between race/ethnicity and productivity following TBI in a non-rehabilitation trauma sample. Results showed that there were no differences between Whites and Hispanics on the Community Integration Questionnaire (CIQ $)^{23}$ Productive Activity subscale ${ }^{24}$. However, these authors found a trend indicating that U.S. born Hispanics had higher scores on the CIQ Productive Activity subscale than non-U.S. born Hispanics.

Less understood is the role that differences in the residential community may play in community participation and integration outcomes after TBI. Rehabilitation research has broadly established that individual perceptions of better environmental quality increase functioning, independence, 
and community reintegration ${ }^{25}$. Specific to TBI, Whiteneck and colleagues reported that perceived barriers in the physical environment, transportation, and healthcare decrease participation after $\mathrm{TBI}^{26}$. Although studies of the specific relationship between environmental characteristics and employment after TBI outcomes are scant, there is reason to believe that successful community reintegration for vulnerable groups, such as racial and ethnic minorities, is particularly sensitive to the economic and social segregation that may be present in the places where people live. Research in the general population demonstrates that neighborhood racial and socioeconomic composition influences how minorities search for and acquire employment, with Hispanics more likely to obtain work through social contacts ${ }^{27}$. Although ethnic enclaves have demonstrated protective effects for many health outcomes, the residential segregation experienced by minorities may place Hispanics with TBI at an added disadvantage for returning to work after injury ${ }^{28}$.

\section{Location and the Influence of Language}

According to the Pew Research Center, the percentage of individuals who speak English in the home or are proficient in English increases with time in the US. However, the rate of increase for adults is well below that of children who are exposed to English in the school system ${ }^{29}$. Immigrants often gravitate to locations where there are high concentrations of immigrants ${ }^{30}$. There is some evidence that living in ethnic enclaves hinders the development of language skills as well as earnings ${ }^{31,32}$. Bauer, Epstein, and Gang (2005) provided some clarification to prior studies and showed that this effect is dependent on the size of the enclave and the level of English proficiency. They concluded that immigrants with low English proficiency tend to gravitate toward larger enclaves out of necessity, whereas individuals with a greater command of 
the English language are attracted to smaller ethnic enclaves, with the latter being a factor in improved language acquisition ${ }^{30}$.

Presently, there are no studies in the research literature that have examined the influence of communities on productive activity outcomes among Hispanic immigrants who have sustained a TBI. The present study sought to better understand how productive activity after TBI may be associated with a complex combination of factors among Hispanics, taking into account the influence of characteristics of the residential community. The National Institute on Disability Independent Living and Rehabilitation Research (NIDILRR) TBI Model Systems (TBIMS) National Database was combined with census data to test the following hypothesis: Differences in the proportion of Spanish-language speakers in the residential community will moderate the relationship between nativity and productive activity at 1 year post-TBI among Hispanics under age 65 (average age of retirement).

\section{Methods}

\section{$\underline{\text { Participants }}$}

Participants were individuals from the TBIMS National Database. Each TBIMS center was approved by their individual Institutional Review Boards. The TBIMS National Database enrollment criteria include: age at least 16 years at time of injury, moderate to severe TBI (as defined by at least one of the following: post-traumatic amnesia greater than 24 hours, traumarelated intracranial neuroimaging abnormalities, loss of consciousness exceeding 30 minutes, or Glasgow Coma Scale score in the emergency department of less than 13); and received acute care hospitalization within 72 hours, followed by inpatient rehabilitation at a TBI Model System of care. 
The present study focused on individuals who identified as Hispanic on a question about Hispanic origin and/or on a question regarding race/ethnicity. Participants were included if they were under age 65 (average retirement age), responded to a question about their place of birth (nativity variable), had complete injury data and productive activity data at 1 year follow-up, and provided their zip code. The sample derivation for the $N=706$ cases included for analysis is illustrated in Figure 1.

\section{Insert Figure 1 About Here.}

The nativity variable was added to the TBIMS National Database in 2012. Due to the longitudinal design of the database with ongoing follow-up $(1,2$, or 5 years post-injury with additional interviews every 5 years), nativity information was collected retrospectively for existing participants enrolled between 1991-2012.

\section{Measures}

The FIM ${ }^{\mathrm{TM}}$ was used to assess functional ability ${ }^{33}$. It indicates the amount of assistance that is required in performing activities of daily living through an 18 -item ordinal scale. Each item is rated on a scale of 1 (requires total assistance) to 7 (completely independent). Total scores range from 18 to 126 . FIM ${ }^{\mathrm{TM}}$ scores obtained at the one-year follow-up time point were used in the present analysis.

Date of emergence from PTA was defined as the first day on which two consecutive passing scores on either the Orientation $\log ^{34}$ or the Galveston Orientation and Amnesia Test ${ }^{35}$, with no more than 72 hours between assessments, was achieved. The number of days in PTA was calculated as the difference between the date of injury (onset of PTA) and the date of emergence from PTA. For individuals who were still in PTA at discharge, length of stay +1 day was 
imputed as has been described previously ${ }^{36}$. This value was used to categorize participants into levels of TBI severity based on the Mississippi intervals ${ }^{37}$. For parsimony in the current analysis, the moderate and moderate-to-severe categories were collapsed into a "moderate" group and the severe and extremely severe categories were collapsed into a "severe" group.

Nativity, education level, and productivity were obtained via interview with the participant or a surrogate. Report of the country of birth was recorded, and for purposes of the present analysis, nativity was divided into two categories: born in the US or born outside of the US. Education level at the time of injury was also divided into two categories for analysis: less than 12 years of education or 12 or more years of education. Productive Activity was obtained at the one-year follow-up, and was operationally defined as being employed, a full-time student, or a volunteer. Residential area characteristics: Residential areas were defined using zip codes reported from participants' home addresses. Aggregate Median Household Income in 2015 inflation-adjusted dollars for participants' zip code was extracted from data collected for the U.S. Census Bureau's American Community Survey (ACS) 5-year estimates obtained from 2011 to 2015. Aggregate Median Household Income was skewed. This variable was categorized using tertile scores representing lower $(<\$ 41,426)$, middle $(\$ 41,426-\$ 56,838)$, and higher $(>\$ 56,838)$ levels of income within the zip codes included in the sample ${ }^{38}$.

Proportion of Foreign Language Speakers (FLS) was calculated as the population estimates of Hispanic individuals speaking a foreign language divided by the total population of Hispanics in each zip code. Residential area data were extracted from the National Historical Geographic Information System (NHGIS; Minnesota Population ${ }^{39}$. Proportion of FLS also showed a skewed distribution. A median split was used to dichotomize this variable into lower $(\leq 80.7 \%)$ and higher (> 80.7\%) proportion groups. 


\section{Analysis}

A hierarchical logistic regression was performed with Productive Activity at 1 year post-TBI as the dependent variable. Nativity and Proportion of FLS were entered on Block 1 with the following covariates: age, PTA classification, education level, Productive Activity at injury, and FIM $^{\mathrm{TM}}$ at follow-up. The interaction between Nativity and Proportion of FLS was entered on Block 2 to determine whether this added any additional predictive value to the model. A BoxTidwell test for linearity within the logit was used for the continuous covariates in the model. Age was linear within the logit but FIM ${ }^{\mathrm{TM}}$ at follow-up was not. Rather than fitting FIM ${ }^{\mathrm{TM}}$ at follow-up as a continuous variable that would require a transformation, it was found that a median split created a sufficient theoretical distinction between those with a mean item score of greater than or less than 6.667 , between the rating categories of complete independence or less than complete independence (modified independence or less), respectively. This dichotomized variable was labeled as Functional Independence.

\section{Results}

\section{$\underline{\text { Demographics and Sample Characteristics }}$}

Of the total sample of 706 participants, $152(21.5 \%)$ were female. Almost half of the sample had less than a $12^{\text {th }}$ grade education. Vehicular accidents accounted for the largest proportion of the sample. Sample characteristics are shown in Table 1.

\section{Insert Table 1 About Here.}

Slightly over half of the sample was born in the US (57.9\%). Of those who were born elsewhere, individuals of Mexican origin made up the largest subgroup, accounting for $52.1 \%$ of foreignborn participants. This was followed by Cuba (8.2\%), Puerto Rico (5.1\%), El Salvador (5.1\%), 
Honduras (5.1\%), and the Dominican Republic (5.1\%). Table 2 shows the breakdown of foreignborn participants by region.

\section{Insert Table 2 About Here.}

Relationships between Nativity and Proportion of FLS with Productivity at 1 year follow-up

On Block 1 of the logistic regression, entry of Nativity and Proportion of FLS with the covariates resulted in a model significantly predicting Productive Activity at 1 year post-TBI $\left(\chi^{2}=305.6, \mathrm{df}\right.$ $=10, p<0.001)$. As can be seen in Table 3, neither Nativity nor Proportion of FLS showed any significant association with Productive Activity in Block 1.

\section{Insert Table 3 About Here.}

On Block 2, the interaction between Nativity and Proportion of FLS was added to the model, resulting in a significant change in the overall model from Block $1,\left(\Delta \chi^{2}=5.3, \Delta \mathrm{df}=1, p=\right.$ 0.022). The complete model with the interaction included, significantly predicted Productive Activity at 1 year post-TBI $\left(\chi^{2}=310.8, \mathrm{df}=11, p<0.001\right)$.

As can be seen in Table 3, the interaction term was significant ( $p=0.023)$; thus the relationships between Nativity and Proportion of FLS with Productivity at 1 year follow-up are interdependent. To further examine the significant interaction effect, the relationship between Proportion of FLS and Productivity was first examined separately for US and non-US born individuals. For those born in the US, there was not a significant relationship between Proportion of FLS and Productivity at 1 year $(p=0.630)$. However, for those who were born outside of the US, there was a significant relationship ( $p=0.018$ ), such that individuals living in areas with a higher Proportion of FLS were 2.82 times more likely to be engaged in Productive Activity at 1 year follow-up compared to those living in areas with a lower proportion of FLS ( $95 \% \mathrm{CI}=1.19$, 6.68). Next, the relationship between Nativity and Productivity was examined separately for 
those individuals living in areas with lower and higher Proportions of FLS. For those living in areas with higher Proportion of FLS, there was not a significant relationship between Nativity and Productivity $(p=0.806)$. However, for those living in areas with lower Proportion of FLS there was a significant relationship $(p=0.005)$, such that US born individuals were 2.70 times more likely to be engaged in Productive Activity at 1 year follow-up compared to non-US born individuals $(95 \% \mathrm{CI}=1.34,5.56)$. These relationships are summarized in Table 4 and illustrated in Figure 2.

Insert Table 4 About Here.

Insert Figure 2 About Here.

\section{Discussion}

This study examined the complex relationship between nativity and productive activity among Hispanics with TBI by considering the influence of living amongst a higher or lower proportion of FLS. After controlling for demographic characteristics, neither nativity nor proportion of FLS was independently associated with productive activity at 1-year post-TBI. However, this analysis found a contingency between nativity and living in a community with a higher proportion of FLS in the likelihood of productive activity at one-year post-TBI. Among foreign-born individuals with TBI, those living in an area with a higher proportion of FLS were 2.8 times more likely to be productive at 1 year follow-up than those living in areas with a lower proportion of FLS. Among individuals living in an area with a lower proportion of FLS, US born Hispanics were 2.7 times more likely to be productive at 1 year follow-up compared with Hispanic immigrants. In addition to the unique findings regarding the impact of proportion of FLS on productivity status, the current results are consistent with prior findings that age $e^{8,40-43}$, education ${ }^{21,41,43-46}$, 
injury severity ${ }^{41,42,47,48}$, productivity at the time of injury ${ }^{8,43}$, and functional or cognitive status $^{40,46,49}$ are associated with productivity status in adults with TBI.

Predictors of productivity specifically for Hispanics have not been investigated in many studies. Ketchum and colleagues (2012) studied predictors of employment in 418 Hispanics with 1 year follow-up data in the TBIMS National Database. The results of the current study are consistent with the findings of Ketchum et al. (2012) in showing that productivity at injury, education, and PTA duration are predictive of productivity in Hispanics; however, the current study builds upon this research by demonstrating that even after controlling for these common predictors of productivity, sociodemographic variables and characteristics of the residential community are significantly associated with outcome.

The results of the present study suggest that, for Hispanics who were not born in the US, living in an area with a higher proportion of FLS appears to convey important benefits in terms of productive activity (being engaged in work, education, or volunteer activity) following TBI. Related findings have been published that show a health-protective effect (i.e., decreased likelihood of problem drinking) of living in neighborhoods with those of similar ethnicity for older Mexican-American men who are non-English speaking ${ }^{50}$. For instance, the better productivity outcomes for foreign-born Hispanics with TBI living in high foreign language dense areas may be due to greater social support being conveyed for members of their community with TBIs.

Future research on this topic is needed to help identify what characteristics of the cultural context in residential areas with higher proportions of FLS play a role in improving return to productivity outcomes in foreign born Hispanics with TBI in the US. 


\section{$\underline{\text { Limitations and Future Directions }}$}

The sample in the current study represented individuals who were admitted to selected inpatient rehabilitation facilities that are part of the TBIMS program. Findings may not generalize to people with TBI treated in other facilities or who did not undergo inpatient rehabilitation after their TBI. Additionally, the analyses in the current study were restricted to those variables collected as part of the TBIMS so information regarding level of literacy or level of English proficiency were not assessed. Therefore, we cannot interpret the impact or contribution of other cultural variables on productivity status. Individuals were only included in the current study if they were younger than 65 years old. As there are individuals who work well beyond 65 years old, the current findings may not be generalizable to the population who works beyond the age of 65 years. Finally, the analysis was limited by missing data. Of the individuals for whom Nativity data was available, $69 \%$ had complete data and were included in the analysis for the current study $(N=706)$.

The findings of this study suggest that systematic differences in the social stratification of the places where people live may partially explain differences in community participation outcomes for Hispanics living with TBI. Within the state/federal vocational rehabilitation program, da Silva Cardoso and colleagues (2007) found that a number of demographic factors (female gender, older age, lower levels of education, work disincentives and co-occurring alcohol and other drug abuse) and the need for transportation services were associated with a decreased odds of employment among Hispanics ${ }^{51}$. Various services - substantial counseling, university training, vocational training, job search assistance, job placement assistance, on-the-job support, maintenance, assistive technology and technical assistance to start a business - were related to 
increased odds of Hispanics being employed. These factors may be useful to include in a vocational rehabilitation program for Hispanics striving to return to productive activity after TBI. In light of the current findings, a comprehensive program should take into account the differences in the composition of the communities where people live post-discharge. Hispanic immigrants living in areas with lower proportions of FLS may be at a particular disadvantage. Language barriers for those with limited English proficiency and other obstacles such as cultural isolation may require more specialized services to achieve equity in productivity outcomes. For many of these individuals, it may be helpful for a vocational rehabilitation program to include training, not only in basic English, but in teaching individuals specific terminology helpful to seeking and acquiring employment, such as what would be necessary for a job interview. In addition, training in health literacy and brain injury education may be beneficial. Inadequate health literacy is associated with poor disease knowledge for some chronic conditions, ${ }^{52-54}$. A study by Pappadis et al. (2011) found that misconceptions regarding TBI were higher among Hispanics who were Spanish-speakers and those who were born outside of the U.S. ${ }^{55}$. Improving health literacy and providing education about TBI may help Hispanic immigrants to better understand the nature of TBI and how it might impact a return to productive activity. Culturally tailored educational interventions have shown promise in reducing misconceptions about $\mathrm{TBI}^{56}$. This educational element can be a part of a comprehensive vocational rehabilitation program to empower individuals toward self-advocacy by not only increasing knowledge, but providing training in how to convey this information to employers. Future research could examine issues associated with the residential community in greater depth and involve measures to capture the perspective of the participants with regard to the barriers and facilitators of productive activity within their communities. Collectively, these studies could 
inform current practices to incorporate additional culturally appropriate elements into patientcentered interventions designed to improve productive activity outcomes within the Hispanic population after TBI. 


\section{References}

1. Selassie AW, Zaloshnja E, Langlois JA, Miller T, Jones P, Steiner C. Incidence of long-term disability following traumatic brain injury hospitalization, United States, 2003. J Head Trauma Rehabil. 2008;23(2):123-131.

2. Thurman DJ, Alverson C, Dunn KA, Guerrero J, Sniezek JE. Traumatic brain injury in the United States: A public health perspective. J Head Trauma Rehabil. 1999;14(6):602-615.

3. Zaloshnja E, Miller T, Langlois JA, Selassie AW. Prevalence of long-term disability from traumatic brain injury in the civilian population of the United States, 2005. J Head Trauma Rehabil. 2008;23(6):394-400.

4. Finkelstein E, Corso PS, Miller TR. The Incidence and Economic Burden of Injuries in the United States. New York: Oxford University Press; 2006.

5. Cuthbert JP, Harrison-Felix C, Corrigan JD, Bell JM, Haarbauer-Krupa JK, Miller AC. Unemployment in the United States after traumatic brain injury for working-age individuals: prevalence and associated factors 2 years postinjury. J Head Trauma Rehabil. 2015;30(3):160174.

6. Juengst SB, Adams LM, Bogner JA, et al. Trajectories of life satisfaction after traumatic brain injury: Influence of life roles, age, cognitive disability, and depressive symptoms. Rehabil Psychol. 2015;60(4):353-364.

7. Corrigan JD, Lineberry LA, Komaroff E, Langlois JA, Selassie AW, Wood KD. Employment after traumatic brain injury: differences between men and women. Arch Phys Med Rehabil. 2007;88(11):1400-1409.

8. Gary KW, Arango-Lasprilla JC, Ketchum JM, et al. Racial differences in employment outcome after traumatic brain injury at 1, 2, and 5 years postinjury. Arch Phys Med Rehabil. 2009;90(10):1699-1707.

9. Grauwmeijer E, Heijenbrok-Kal MH, Haitsma IK, Ribbers GM. A prospective study on employment outcome 3 years after moderate to severe traumatic brain injury. Arch Phys Med Rehabil. 2012;93(6):993-999.

10. Ketchum JM, Almaz Getachew M, Krch D, et al. Early predictors of employment outcomes 1 year post traumatic brain injury in a population of Hispanic individuals. NeuroRehabilitation. 2012;30(1):13-22.

11. Shigaki CL, Johnstone B, Schopp LH. Financial and vocational outcomes 2 years after traumatic brain injury. Disabil Rehabil. 2009;31(6):484-489.

12. Wagner AK, Hammond FM, Sasser HC, Wiercisiewski D. Return to productive activity after traumatic brain injury: relationship with measures of disability, handicap, and community integration. Arch Phys Med Rehabil. 2002;83(1):107-114.

13. Walker WC, Marwitz JH, Kreutzer JS, Hart T, Novack TA. Occupational categories and return to work after traumatic brain injury: a multicenter study. Arch Phys Med Rehabil. 2006;87(12):1576-1582.

14. Flores A. How the U.S. Hispanic population is changing. 2017; http://www.pewresearch.org/fact-tank/2017/09/18/how-the-u-s-hispanic-population-ischanging/. Accessed September 18, 2017.

15. Passel JS, Cohn D. U.S. Population Projections: 2005-2050. 2008; http://www.pewsocialtrends.org/2008/02/11/us-population-projections-2005-2050/. Accessed September 18, 2017.

16. DeNavas-Walt C, Proctor BD. Income and Poverty in the United States: 2013. 2014; https://www.census.gov/content/dam/Census/library/publications/2014/demo/p60-249.pdf. Accessed September 17, 2017. 
17. Bureau USC. Selected Population Profile in the United States. 2016; https://factfinder.census.gov. Accessed September 17, 2017.

18. Sevak P, Houtenville AJ, Brucker DL, O'Neill J. Individual Characteristics and the Disability Employment Gap. Journal of Disability Policy Studies. 2015;26(2):80-88.

19. Rosenthal M, Dljkers M, Harrison-Felix C, et al. Impact of Minority Status on Functional Outcome and Community Integration Following Traumatic Brain Injury. The Journal of Head Trauma Rehabilitation. 1996;11(5):40-57.

20. Arango-Lasprilla JC, Ketchum JM, Gary KW, et al. The influence of minority status on job stability after traumatic brain injury. PM R. 2009;1(1):41-49.

21. Kreutzer JS, Marwitz JH, Walker W, et al. Moderating factors in return to work and job stability after traumatic brain injury. J Head Trauma Rehabil. 2003;18(2):128-138.

22. Arango-Lasprilla JC, Ketchum JM, Lewis AN, Krch D, Gary KW, Dodd BA, Jr. Racial and ethnic disparities in employment outcomes for persons with traumatic brain injury: a longitudinal investigation 1-5 years after injury. PM R. 2011;3(12):1083-1091.

23. Willer B, Ottenbacher KJ, Coad ML. The community integration questionnaire. A comparative examination. Am J Phys Med Rehabil. 1994;73(2):103-111.

24. Sander AM, Pappadis MR, Davis LC, et al. Relationship of race/ethnicity and income to community integration following traumatic brain injury: investigation in a non-rehabilitation trauma sample. NeuroRehabilitation. 2009;24(1):15-27.

25. Magasi S, Wong A, Gray DB, et al. Theoretical foundations for the measurement of environmental factors and their impact on participation among people with disabilities. Arch Phys Med Rehabil. 2015;96(4):569-577.

26. Whiteneck GG, Gerhart KA, Cusick CP. Identifying environmental factors that influence the outcomes of people with traumatic brain injury. J Head Trauma Rehabil. 2004;19(3):191-204.

27. Elliott JR, Sims M. Ghettos and Barrios: The Impact of Neighborhood Poverty and Race on Job Matching among Blacks and Latinos. Social Problems. 2001;48(3):341-361.

28. Liu CY. Ethnic enclave residence, employment, and community of Latino workers. Journal of Policy Analysis and Management. 2009;28(4):600-625.

29. Krogstad JM, Stepler R, Lopez MH. English Proficiency on the Rise Among Latinos: U.S. Born Driving Language Changes. 2015; http://www.pewhispanic.org/2015/05/12/english-proficiencyon-the-rise-among-latinos/. Accessed September 14, 2017.

30. Bauer T, Epstein G, Gang I. Enclaves, language, and the location choice of migrants. Journal of Population Economics. 2005;18(4):649-662.

31. Chiswick BR, Miller PW. Do Enclaves Matter in Immigrant Adjustment? City \& Community. 2005;4(1):5-35.

32. Warman C. Ethnic Enclaves and Immigrant Earnings Growth. The Canadian Journal of Economics. 2007;40(2):401-422.

33. Keith RA, Granger CV, Hamilton BB, Sherwin FS. The functional independence measure: a new tool for rehabilitation. Adv Clin Rehabil. 1987;1:6-18.

34. Jackson WT, Novack TA, Dowler RN. Effective serial measurement of cognitive orientation in rehabilitation: the Orientation Log. Arch Phys Med Rehabil. 1998;79(6):718-720.

35. Levin HS, O'Donnell VM, Grossman RG. The Galveston Orientation and Amnesia Test. A practical scale to assess cognition after head injury. J Nerv Ment Dis. 1979;167(11):675-684.

36. Nakase-Richardson R, Yablon SA, Sherer M. Prospective comparison of acute confusion severity with duration of post-traumatic amnesia in predicting employment outcome after traumatic brain injury. J Neurol Neurosurg Psychiatry. 2007;78(8):872-876.

37. Nakase-Richardson R, Sepehri A, Sherer M, Yablon SA, Evans C, Mani T. Classification schema of posttraumatic amnesia duration-based injury severity relative to 1-year outcome: analysis of 
individuals with moderate and severe traumatic brain injury. Arch Phys Med Rehabil. 2009;90(1):17-19.

38. Gelman A, Park DK. Splitting a predictor at the upper quarter or third and the low quarter or third. The American Statistician. 2008;62(4).

39. Center MP. National Historical Geographic Information System: Version 11.0 [Database]. 2016; http://doi.org/10.18128/D050.V11.0, 2016.

40. Devitt R, Colantonio A, Dawson D, Teare G, Ratcliff G, Chase S. Prediction of long-term occupational performance outcomes for adults after moderate to severe traumatic brain injury. Disabil Rehabil. 2006;28(9):547-559.

41. Doctor JN, Castro J, Temkin NR, Fraser RT, Machamer JE, Dikmen SS. Workers' risk of unemployment after traumatic brain injury: a normed comparison. J Int Neuropsychol Soc. 2005;11(6):747-752.

42. Fraser R, Machamer N, Temkin N, Dikmen S, Doctor J. Return to work in traumatic brain injury (TBI): A perspective on capacity for job complexity. Journal of Vocational Rehabilitation. 2006;25:141-148.

43. Schonberger M, Ponsford J, Olver J, Ponsford M, Wirtz M. Prediction of functional and employment outcome 1 year after traumatic brain injury: a structural equation modelling approach. J Neurol Neurosurg Psychiatry. 2011;82(8):936-941.

44. Gary KW, Arango-Lasprilla JC, Stevens LF. Do racial/ethnic differences exist in post-injury outcomes after TBI? A comprehensive review of the literature. Brain Inj. 2009;23(10):775-789.

45. Keyser-Marcus LA, Bricout JC, Wehman P, et al. Acute predictors of return to employment after traumatic brain injury: a longitudinal follow-up. Arch Phys Med Rehabil. 2002;83(5):635-641.

46. Sherer M, Sander AM, Nick TG, High WM, Jr., Malec JF, Rosenthal M. Early cognitive status and productivity outcome after traumatic brain injury: findings from the TBI model systems. Arch Phys Med Rehabil. 2002;83(2):183-192.

47. Andelic N, Stevens LF, Sigurdardottir S, Arango-Lasprilla JC, Roe C. Associations between disability and employment 1 year after traumatic brain injury in a working age population. Brain Inj. 2012;26(3):261-269.

48. Cifu DX, Keyser-Marcus L, Lopez E, et al. Acute predictors of successful return to work 1 year after traumatic brain injury: a multicenter analysis. Arch Phys Med Rehabil. 1997;78(2):125-131.

49. O'Connell MJ. Prediction of return to work following traumatic brain injury: Intellectual, memory, and demographic variables. . Rehabilitation Psychology. 2000;45:212-217.

50. Stroope S, Martinez BC, Eschbach K, Peek MK, Markides KS. Neighborhood Ethnic Composition and Problem Drinking Among Older Mexican American Men: Results from the Hispanic Established Populations for the Epidemiologic Study of the Elderly. J Immigr Minor Health. 2015;17(4):1055-1060.

51. da Silva Cardoso E, Romero MG, Chan F, Dutta A, Rahimi M. Disparities in vocational rehabilitation services and outcomes for Hispanic clients with traumatic brain injury: do they exist? J Head Trauma Rehabil. 2007;22(2):85-94.

52. Gazmararian JA, Williams MV, Peel J, Baker DW. Health literacy and knowledge of chronic disease. Patient Educ Couns. 2003;51(3):267-275.

53. Magasi S, Durkin E, Wolf MS, Deutsch A. Rehabilitation consumers' use and understanding of quality information: a health literacy perspective. Arch Phys Med Rehabil. 2009;90(2):206-212.

54. Pandit AU, Tang JW, Bailey SC, et al. Education, literacy, and health: Mediating effects on hypertension knowledge and control. Patient Educ Couns. 2009;75(3):381-385.

55. Pappadis MR, Sander AM, Struchen MA, Leung P, Smith DW. Common misconceptions about traumatic brain injury among ethnic minorities with TBI. J Head Trauma Rehabil. 2011;26(4):301-311. 
56. Pappadis MR, Sander AM, Lukaszewska B, Struchen MA, Leung P, Smith DW. Effectiveness of an Educational Intervention on Reducing Misconceptions Among Ethnic Minorities With Complicated Mild to Severe Traumatic Brain Injury. Arch Phys Med Rehabil. 2017;98(4):751-758. 


\section{Figure Captions}

Figure 1: Sample Derivation

Figure 2: Productive Activity as a Function of Nativity and Proportion of Foreign Language Speakers 
Table 1: Demographics, Descriptive Statistics, and Injury Characteristics

\begin{tabular}{|c|c|c|}
\hline Nominal Variables & $N$ & Percent \\
\hline \multicolumn{3}{|l|}{ Sex } \\
\hline Female & 152 & 21.5 \\
\hline Male & 554 & 78.5 \\
\hline \multicolumn{3}{|l|}{ Nativity } \\
\hline Born in the US & 409 & 57.9 \\
\hline Foreign-born & 297 & 42.1 \\
\hline \multicolumn{3}{|l|}{ Education } \\
\hline Less Than 12th Grade & 334 & 47.3 \\
\hline High School Diploma & 174 & 24.7 \\
\hline Beyond High School & 198 & 28.0 \\
\hline \multicolumn{3}{|l|}{ Severity of Injury } \\
\hline Moderate & 374 & 53.0 \\
\hline Severe & 332 & 47.0 \\
\hline \multicolumn{3}{|l|}{ Cause of Injury } \\
\hline Vehicular & 443 & 63.7 \\
\hline Assault & 104 & 14.9 \\
\hline Sports or other & 19 & 2.7 \\
\hline Fall & 130 & 18.7 \\
\hline [Unknown] & [10] & \\
\hline Continuous Variables & Mean & SD \\
\hline Age at Injury & 32.6 & 13.4 \\
\hline FIM ${ }^{\mathrm{TM}}$ Total at Admission & 48.4 & 21.6 \\
\hline FIM ${ }^{\mathrm{TM}}$ Total at Discharge & 88.4 & 22.1 \\
\hline FIM ${ }^{\mathrm{TM}}$ Total at Follow-up & 111.8 & 19.7 \\
\hline
\end{tabular}

Note: $S D=$ standard deviation 
Table 2: Place of Birth for Hispanics Born Outside of the US

\begin{tabular}{lcc}
\hline Region of Birth & $N$ & Percent \\
\hline Central America & 198 & 67.6 \\
Caribbean & 59 & 20.1 \\
South America & 30 & 10.2 \\
Europe & 4 & 1.4 \\
Asia & 1 & 0.3 \\
Africa & 1 & 0.3 \\
[Unknown] & {$[4]$} & \\
\hline
\end{tabular}


Table 3: Logistic Regression Predicting Productive Activity at 1 Year Follow-Up

\begin{tabular}{|c|c|c|c|}
\hline Block 1: Variables Entered & $p$-value & OR & $95 \% \mathrm{CI}$ \\
\hline Age & 0.016 & 0.98 & $(0.97,0.99)$ \\
\hline Severe Injury compared with Moderate & $<0.001$ & 0.33 & $(0.22,0.49)$ \\
\hline Productive Activity at Injury & $<0.001$ & 4.18 & $(2.22,7.88)$ \\
\hline \multicolumn{4}{|l|}{ Education $^{a}$} \\
\hline High School & 0.741 & 1.09 & $(0.66,1.78)$ \\
\hline Beyond High School & $<0.001$ & 2.36 & $(1.46,3.82)$ \\
\hline Functional Independence at Follow-up & $<0.001$ & 9.88 & $(6.58,14.85)$ \\
\hline \multicolumn{4}{|l|}{ Aggregate Median Household Income } \\
\hline Middle compared with Low & 0.055 & 1.63 & $(0.99,2.69)$ \\
\hline High compared with Low & 0.083 & 1.63 & $(0.94,2.85)$ \\
\hline Foreign Born compared with US Native & 0.135 & 0.72 & $(0.46,1.11)$ \\
\hline Higher Proportion of FLS & 0.274 & 1.30 & $(0.81,2.06)$ \\
\hline Block 2: Variables Entered & $p$-value & OR & $95 \% \mathrm{CI}$ \\
\hline Age & 0.012 & 0.98 & $(0.96,0.99)$ \\
\hline Severe Injury compared with Moderate & $<0.001$ & 0.32 & $(0.21,0.48)$ \\
\hline Productive Activity at Injury & $<0.001$ & 4.11 & $(2.18,7.75)$ \\
\hline \multicolumn{4}{|l|}{ Education $^{a}$} \\
\hline High School & 0.616 & 1.14 & $(0.69,1.87)$ \\
\hline Beyond High School & 0.001 & 2.35 & $(1.45,3.82)$ \\
\hline Functional Independence at Follow-up & $<0.001$ & 10.03 & $(6.65,15.11)$ \\
\hline \multicolumn{4}{|l|}{ Aggregate Median Household Income } \\
\hline Middle compared with Low & 0.035 & 1.72 & $(1.04,2.83)$ \\
\hline High compared with Low & 0.062 & 1.70 & $(0.97,2.96)$ \\
\hline Foreign Born compared with US Native & 0.008 & 0.40 & $(0.20,0.79)$ \\
\hline Higher Proportion of FLS & 0.696 & 0.89 & $(0.51,1.57)$ \\
\hline Nativity $\times$ Proportion of FLS & 0.023 & 2.77 & $(1.15,6.67)$ \\
\hline
\end{tabular}

Note: $O R=$ Odds Ratio, $C I=$ Confidence Interval, $F L S=$ Foreign Language Speakers

${ }^{a}$ Reference category: Less than 12 years of education/no diploma 
Table 4: Odds Ratios for Nativity by Proportion of FLS Interaction on Productive Activity at 1 Year Follow-Up

\begin{tabular}{ccccc}
\hline & Proportion & & & \\
Nativity & FLS & $p$-value & OR & $95 \%$ CI \\
\hline US Born & High vs. Low & 0.630 & 0.87 & $(0.49,1.54)$ \\
Non-US Born & High vs. Low & 0.018 & 2.82 & $(1.19,6.68)$ \\
\hline US-Born vs. Non-US Born & Low & 0.005 & 2.72 & $(1.36,5.44)$ \\
US-Born vs. Non-US Born & High & 0.806 & 0.93 & $(0.51,1.69)$ \\
\hline
\end{tabular}

Note: $O R=$ Odds Ratio, $C I=$ Confidence Interval, FLS = Foreign Language Speakers 


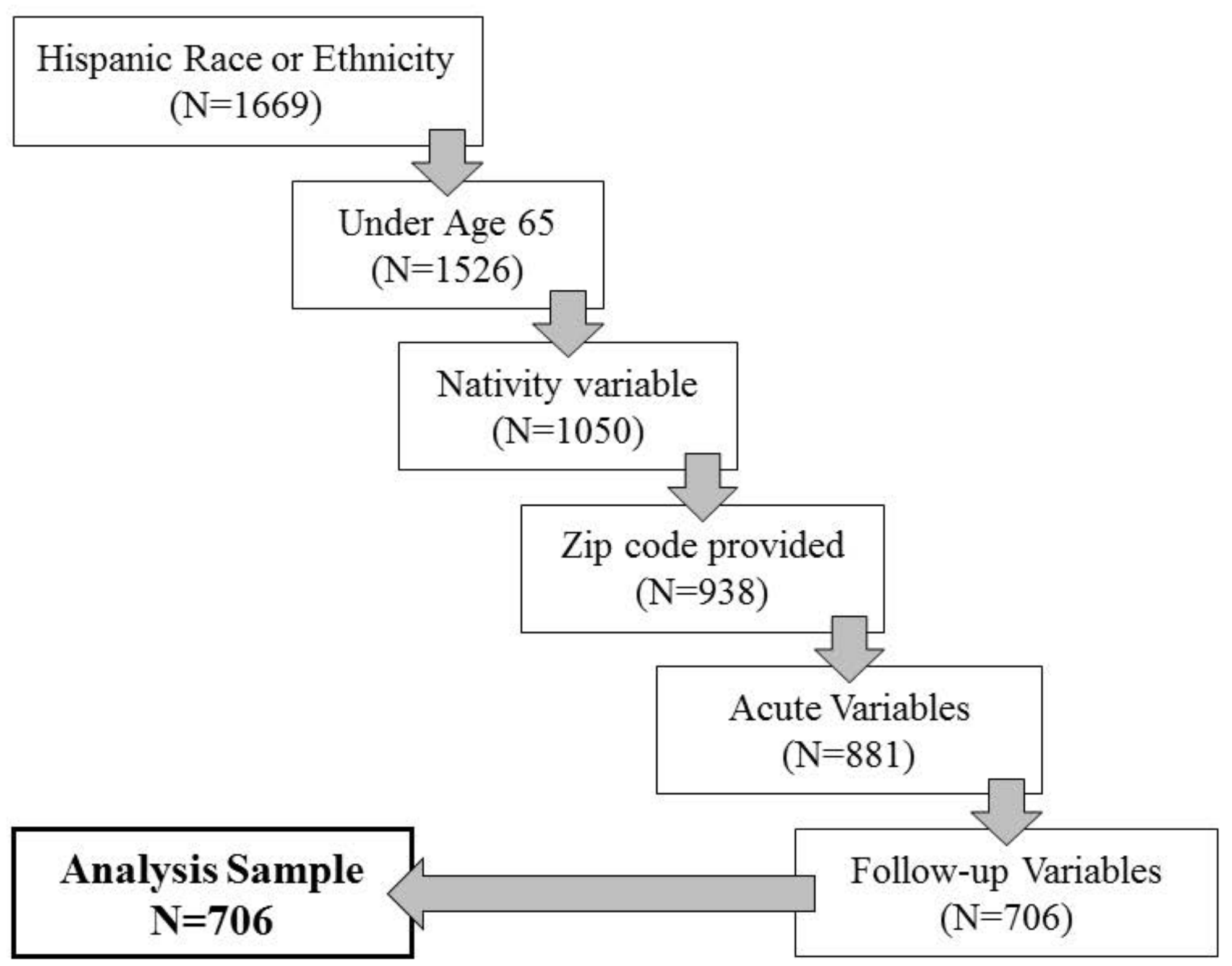




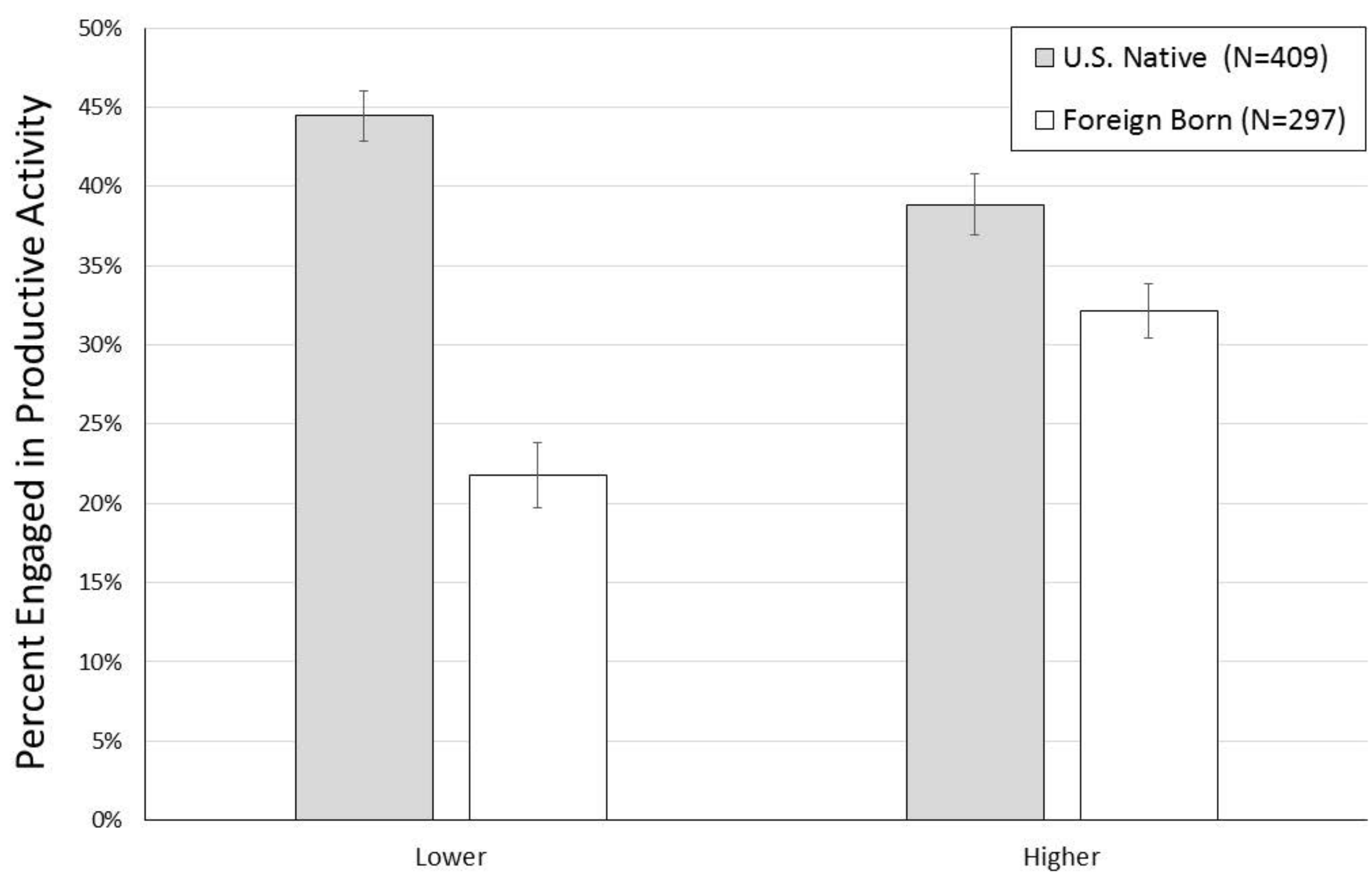

Residential Proportion of Foreign Language Speakers 